\title{
ADAPTAÇÃO DAS PLANTAS AO FOGO: ENFOQUE NA TRANSIÇÃO FLORESTA - CAMPO
}

\author{
PLANTS ADAPTATION TO BURNING: FOREST-GRASSLAND TRANSITION
}

\author{
Ingrid Heringer $^{1}$ Aino Victor Ávila Jacques ${ }^{2}$
}

- REVISÃO BIBLIOGRÁFICA -

\section{RESUMO}

A presença de campos entremeados pela floresta de araucária, na região do planalto meridional sul brasileiro, surpreende os estudiosos, pois a vigorar o clima atual, de maiores precipitações, a tendência seria o desenvolvimento de vegetação florestal. Os distúrbios, sobretudo a interação fogo-pastejo, e as baixas temperaturas da região, são os grandes responsáveis pelos limites e expansão da floresta latifoliada, e predomínio daquele tipo de vegetação. A vegetação campestre e arbórea submetida por longo período a fogos recorrentes desenvolveu uma série de estratégias no sentido de tolerar, evitar ou responder ao fogo. A resposta individual das plantas ao fogo envolve alterações morfológicas e fisiológicas, enquanto, na comunidade, observam-se mudanças na dinâmica da associação entre espécies. $\mathrm{Na}$ vegetação campestre, as gramíneas são o componente da comunidade mais tolerante ao fogo, devido ao contínuo crescimento dos meristemas intercalares e de novos afilhos que crescem protegidos no solo ou na bainha de folhas velhas. O fogo estimula o florescimento em plantas cuja forma de crescimento evita grande perda de material na queima. Também promove a liberação de sementes através do choque térmico ou de substâncias liberadas na fumaça. Na comunidade, os efeitos do fogo sobre as plantas são sentidos em relação ao modo de sobrevivência, natureza e localização dos tecidos regenerados. O comportamento das plantas em relação à queima pode ser como dependentes (estímulo à reprodução), resistentes (estímulo ao rebrote), ou plantas que evitam o fogo (ciclo anual). Portanto, o fogo tem complexos efeitos sobre a estrutura da vegetação, sendo que espécies vegetais sensíveis e tolerantes à queima tem diferentes sítios de preferencia no ambiente.
Palavras-chave: fogo, pastagem natural, floresta, ecofisiologia.

\section{SUMMARY}

The presence of grassland alternating with Araucarian forest in Southern Brazilian plateau, has surprised the scientists, as to be in force the current climate, of greater precipitation than in remote times, the tendency would be the development of forest vegetation. Disturbances, specially firegrazing interaction and low temperacture in the region, are the greater responsible for the boundaries and expansion of broadleaf forest, and dominance of that vegetation type. The grassland and forest vegetation submitted for long period to recurrent fires have developed strategies to tolerate, avoid or respond to fire. The response of individual plants involve morphological and physiological changes, while at the community level such changes are observed in the dinamics of association among species. Under range conditions, the grasses are the most fire tolerant component in the community, due to the continuous growth of intercalar meristems and also to the new shoots which grow below soil surface or protected in old sheat leaf. Fire stimulates flowering in plants whose growth form is able to avoid greater loss of matter during the burning period. Fire also promotes the release of seeds due to changes in temperature or the release of substances from smoke. At the community level, fire effects on the plants ocurr in relation to the way of surviving and nature and localization of regeneration tissues. The plant behaviour in relation to burning may be classified as dependent (stimulus to reproduction), resistant (stimulus to new shoot), or plants that avoid fire (annual cycle). Therefore, fire has complex effects on the vegetation structure,

${ }^{1}$ Zootecnista, MSc., aluno do curso de doutorado em Zootecnia, Universidade Federal do Rio Grande do Sul (UFRGS), bolsista do CNPq. E-mail: renato@prezzotto.com.br. Autor para correspondência.

${ }^{2}$ Engenheiro agronômo, PhD., Professor Titular, Departamento de Plantas Forrageiras e Agrometeorologia, Pesquisador do CNPq, UFRGS, CP 776, Av. Bento Gonçalves, 7712, 91570-970, Porto Alegre, RS. 
resulting that tolerant and sensitive species have had different preference patches in the environment.

Key words: fire, natural pasture, forest, ecophysiology.

\section{INTRODUÇÃO}

A presença dos campos no planalto meridional sul brasileiro representa um relicto de um clima anterior frio e seco (RAMBO, 1953; KLEIN, 1984). A medida em que a temperatura e, sobretudo, a precipitação aumentaram, houve a expansão da floresta tropical nos vales e, mais tarde, migração da mata de araucária dos vales para as montanhas. O período de maior expansão da araucária coincidiu com um período de alta freqüência de fogos, que pode estar relacionada ao aumento na população indígena no final do Holoceno (BEHLING, 1995; BEHLING, 1997). A presença dos campos nos dias atuais, no entanto, está em desarmonia com o clima atual, com alta precipitação (HOLDRIGE, 1947; RAMBO, 1953; KLEIN, 1984; BEHLING, 1995). A vigorar este clima, subtropical, temperado-úmido, com precipitações entre 1000 e $2000 \mathrm{~mm} / \mathrm{ano}$, a tendência é de haver desenvolvimento de vegetação florestal (HOLDRIGE, 1947), portanto, com tendência de a mata invadir o campo. Entretanto, fatores edáficos, paleofogos (BEHLING, 1997) e a herbivoria mais intensa e, por vezes, desordenada, orientada pelo homem, parecem ter papel fundamental na manutenção do campo entremeado por floresta na região dos campos de altitude.

Os campos naturais sul americanos devem ter evoluído sob um regime de distúrbios que incluem a herbivoria e o fogo. As mudanças no clima, no tipo de vegetação, na população humana e nos herbívoros alteraram o regime de queimadas nos últimos 13 mil anos, que têm apresentado intensidade decrescente e freqüência crescente (SCHÜLE, 1990; BEHLING, 1995). Esse comportamento está bastante ligado ao pastejo, que passou a ser cada vez mais intenso e sem ajuste da carga animal, orientado pelo homem, desde a entrada de herbívoros domésticos trazidos pelos colonizadores europeus.

Analisando a transição floresta e campos na região sul do Brasil e a divergência entre vegetação observada e a predita pelos modelos climáticos, PILLAR \& QUADROS (1997) levantam hipóteses sobre a influência do fogo na dinâmica da vegetação em períodos remotos. Os autores especulam que a ocorrência do fogo de forma espontânea ou por influência do homem pode ter contribuído para definir a localização e limites da Mata de Araucária e servido como uma barreira para a expansão de outros tipos florestais mais sensíveis à queima.
Portanto, tudo indica que as plantas ao longo de sua evolução, desenvolveram características morfofisiológicas que facilitam sua combustão, como forma de eliminar espécies mais competitivas, porém pouco tolerantes às queimas periódicas (STEUTER \& McPHERSON, 1995; BOND \& WILGEN, 1996). Há uma forte interação entre fogo e pastejo no comportamento das espécies, sendo que plantas aptas a reduzir a herbivoria promovem a "herbivoria" pelo fogo. As propriedades químicas e morfológicas das espécies individuais, freqüentemente associadas às defesas contra herbívoros e a adaptação para sobreviver à seca, bem como o arranjo de comunidades no espaço, influenciam a susceptibilidade destas ao fogo (RISSER, 1990; BOND \& WILGEN, 1996). Portanto, é uma ironia da ecologia do fogo que plantas rapidamente consumidas pelo fogo e destituídas de maior capacidade para revegetar, freqüentemente dominem a vegetação de áreas queimadas (WALLACE, 1990).

\section{DESENVOLVIMENTO}

\section{Ecologia da araucária e a sua tolerância ao fogo nos campos de altitude}

Estudos paleobotânicos, conduzidos no Planalto Meridional Brasileiro por BEHLING (1995), apontam para um grande predominância de Poaceae e Cyperaceae do início do Holoceno (12 480 anos atrás), até 2850 anos atrás. A partir desta fase inicia o desenvolvimento da floresta de araucária (Araucaria angustifolia, Podocarpus, Mimosa, etc.), que atinge a máxima cobertura entre 1530 e 530 anos atrás. A expansão da floresta de araucária sobre os campos no planalto meridional brasileiro é coincidente com o aumento da população indígena da região, da exploração da vegetação e da frequiência de uso do fogo, visando facilitar a caça e os cultivos agrícolas.

No início do século XX, existia em torno de $40 \%$ de cobertura florestal no Estado do Rio Grande do Sul (RAMBO, 1953). Em 1982, no inventário florestal, foi estimada uma cobertura florestal de 1.585.731ha, correspondente a 5,62\% da superfície do Estado. Deste total, as florestas de araucária representavam uma superfície de 186.658ha, ou seja, apenas $0,07 \%$ da cobertura florestal original (BRASIL, 1983).

Fazendo uma comparação destes resultados com os obtidos no Inventário do Pinheiro no Sul do Brasil (BRASIL, 1978), realizado em 1978, o qual indicou uma superfície de 274.256 ha de florestas de araucária no Rio Grande do Sul, constatase uma redução de $32 \%$ da área de cobertura de araucária, no período de 4 anos. 
Embora usualmente se diga que a araucária é uma espécie pioneira, ela não apresenta comportamento típico que se enquadre nesta definição. Espécie pioneira é aquela que depende de alta irradiância, dissemina-se através de sementes pequenas e em grande quantidade, apresenta crescimento rápido e tem longevidade da planta relativamente curta (SOARES, 1990; DUARTE, 1997). Portanto, a alegação de que a araucária invade sobre o campo porque é uma espécie pioneira não está correta.

Segundo o comportamento apresentado pela araucária, ela é uma espécie seral, que só permanece na vegetação de um local quando existe um distúrbio que impede a sucessão. O melhor desenvolvimento da espécie ocorre em regiões com precipitações acima de $1400 \mathrm{~mm}$, nas maiores altitudes, onde há geadas freqüentes e baixas temperaturas, que são condições que limitam o desenvolvimento e expansão da Floresta Pluvial (BEHLING, 1995; DUARTE, 1997). Pelo fato de a araucária ser uma espécie heliófita, fica muito exposta ao fogo no campo, que é onde geralmente germina e cresce (FERREIRA \& IRGANG, 1979).

Os pinhões caem em abril e maio, apresentando viabilidade das sementes de somente seis semanas (AUBREVILLE, 1949), o que torna a reprodução desta espécie muito difícil. Como as queimadas das pastagens naturais usualmente são feitas entre agosto e setembro, as plântulas que se estabeleceram no outono tem chance de sobreviver somente se o fogo for pouco intenso e se estas estiverem protegidas das chamas. Até a altura de dois metros, a planta é bastante susceptível ao fogo, o que corresponde a uma idade de 5 a 6 anos (SOARES, 1990).

Outras características que podem ser consideradas em relação à proteção e tolerância das plantas ao fogo, são: casca com espessura acima de $5-10 \mathrm{~cm}$, ponto de crescimento elevado acima da altura provável das chamas e plantas crescendo juntas em agrupamentos. Em geral, a tolerância de espécies arbóreas à queima (BOND \& WILGEN, 1996) depende do grau de proteção das gemas ao calor (que é função da espessura da casca e idade da planta), e do nível de chamuscação da coroa (que depende do comprimento das chamas, da arquitetura da planta e de sua velocidade de crescimento).

Algumas observações atestam que a araucária é bastante susceptível aos fogos naturais, por ocasiões de tempestades com raios, e isso provavelmente ocorre devido à presença de oleoresina, em concentrações de 2,51 a $13,40 \%$, na casca da araucária (FERNANDES, 1982). SOARES (1990) comenta que em $20 \%$ dos fogos naturais há incidência sobre plantas de araucária.

\section{Adaptação das plantas ao fogo}

Os distúrbios podem ser considerados elementos básicos na composição da vegetação, incluíndo-se entre esses o fogo e o pastejo (COLLINS \& GIBSON, 1990). O fogo pode ser considerado um efetivo "herbívoro" de muitas comunidades, podendo afetar cerca de $70 \%$ das áreas de vegetação no mundo (BOND \& WILGEN, 1996).

O fogo afeta diretamente o crescimento, a sobrevivência e reprodução das plantas e ainda atua sobre a dinâmica do banco de sementes. É um dos poucos distúrbios que mata plantas adultas, abrindo espaços e promovendo a sucessão vegetal e contribuindo para que acentuadas mudanças ocorram na composição florística das pastagens naturais (STEUTER \& McPHERSON, 1995; BOND \& WILGEN, 1996). A adaptação das plantas e comunidades ao fogo evoluiu sob determinadas condições ambientais em uma escala temporal e espacial (STEUTER \& McPHERSON, 1995), sendo a extensão do distúrbio ajustada às variações climáticas e topográficas.

O fogo pode estressar plantas individuais por consumir reservas que sustentam o crescimento, bem como comunidades de plantas por reduzir a fertilidade e umidade do solo através do aumento na evapotranspiração e escorrimento superficial (STEUTER \& McPHERSON, 1995). Enquanto em pequena escala os indivíduos têm respostas morfofisiológicas ao fogo, em grande escala, ocorre uma dinâmica de mosaico da vegetação, que muda de acordo com a interação entre diferentes distúrbios, resultante de aceleradas taxas de extinção, introdução e fragmentação de plantas (GRIME \& CAMPBELL, 1991; STEUTER \& McPHERSON, 1995; BOND \& WILGEN, 1996).

As adaptações morfofisiológicas das plantas ao fogo envolvem estratégias de resistência, regeneração ou sobrevivência (RIZZINI, 1976; COUTINHO, 1977; STEUTER \& McPHERSON, 1995). A sobrevivência das plantas ao fogo depende, em ordem decrescente, do grau de proteção das gemas, do nível de chamuscação (altamente associado ao material morto ligado à planta), e do intervalo entre queimadas (STEUTER \& McPHERSON, 1995). Plantas com menor relação folha/colmo, colmos mais espessos, baixa produção de material morto na época seca e maior massa residual após a queima, são melhor adaptadas à queima (MACEDO, 1995). A maior eficiência de algumas espécies em áreas queimadas pode ser em função de sua plasticidade fisiológica, devido a qual essas espécies apresentam maior fotossíntese, condutância foliar, concentração de $\mathrm{N}$ na folha e aumento na eficiência de uso da água durante a seca, por desenvolver menor 
potencial osmótico, em relação às plantas de áreas não queimadas (KNAPP, 1985).

As gramíneas são apontadas como a família vegetal melhor adaptada à queima, em função de sua rápida capacidade de regeneração após a queima (DAUBENMIRE, 1968; VOGL, 1974; COUTINHO, 1994). Isto se deve ao contínuo crescimento foliar do meristema intercalar e de novos afilhos, oriundos de meristemas protegidos abaixo do solo ou na base das bainhas persistentes (BOND \& WILGEN, 1996). Por outro lado, as condições ambientais após o fogo, representadas por elevada temperatura e evaporação da superfície de solo descoberto, promovem o desenvolvimento de plantas xerofiticamente adaptadas, com folhas finas e pilosas e menor transpiração (STEUTER \& McPHERSON, 1995).

A elevação da temperatura junto à base das plantas durante a queima tem importância fundamental no grau de distúrbio dessas. Plantas prostradas parecem ser mais sujeitas à queima do que espécies eretas, cujos pontos de crescimento estão mais protegidos no interior da touceira (ESTIVALET, 1997). O exemplo de FONTANELI \& JACQUES (1988) mostra que o reestabelecimento da cobertura de Paspalum notatum Flügge, uma planta rasteira e a principal espécie forrageira dos campos nativos da Depressão Central do RS, leva até cinco meses para ocorrer após a queima. Em relação à estrutura das plantas, todas as formas de crescimento que sofrem pequena perda de biomassa durante a queima, induzem o rápido direcionamento de recursos para a reprodução. Já espécies com grande perda de biomassa persistirão somente através de um banco de sementes (BOND \& WILGEN, 1996).

O fogo tem complexos efeitos sobre a reprodução, estimulando algumas espécies que aumentam o florescimento, a germinação de sementes e o número de plântulas. Isto determinou que algumas espécies, as quais podem se extinguir se o fogo for suprimido, criassem, inclusive, dependência do fogo para se reproduzir (BOND \& WILGEN, 1996). Como principais estímulos do fogo ao florescimento das plantas (STEUTER \& McPHERSON, 1995) citam-se: mudanças na temperatura, na luz e na concentração de nutrientes e a presença de etileno na fumaça.

$\mathrm{O}$ estímulo do fogo à liberação de sementes ocorre em espécies que acumulam sementes num banco reservado no dossel de plantas, que persistam em inflorescências ou protejam-se por tegumentos rígidos (COUTINHO, 1994; BOND \& WILGEN, 1996). Os mecanismos relacionados com a liberação são: choque de calor e liberação de substâncias químicas na fumaça (etileno e amônia), que aumentam a permeabilidade dos tegumentos da semente (STEUTER \& McPHERSON, 1995). Já os mecanismos específicos de estímulo do fogo à germinação e crescimento são: elevação do conteúdo de nutrientes no banco de sementes do solo, presença de gases na fumaça e substâncias químicas que permeiam o embrião induzindo a mudanças enzimáticas que desencadeiam a germinação (BLANK \& YOUNG, 1998). Também a condição pós fogo pode apresentar algumas vantagens para as novas plântulas, como espaço aberto, oferta de recursos (luz, temperatura e nutrientes) e menor número de predadores (DAUBENMIRE, 1968; GRIME, 1979; CHRISTENSEN, 1985).

Às condições previamente referidas, por outro lado, podem associar-se a redução no vigor de algumas espécies forrageiras, e/ou perda de fertilidade do solo, que facilitam o surgimento de espécies oportunistas (ROSENGURTT, 1943), geralmente sem valor forrageiro. Estas espécies efêmeras que, segundo GRIME (1979), possuem grande plasticidade morfofisiológica, tem desenvolvimento breve mas "explosivo", sendo capazes de explorar ambientes produtivos, mas temporário. Os dados de FRANGI et al. (1980), em pastagem natural na Argentina, queimada acidentalmente no final da estação fria, ilustram bem esta situação. Após a queima, houve aumento na diversidade taxonômica, quando a área aberta foi rapidamente ocupada por dicotiledôneas em detrimento, principalmente, das gramíneas nativas hibernais, tais como os gêneros: Bromus, Stipa e Piptochaetium. Enquanto as gramíneas mantiveram a mesma produção de fitomassa, as dicotiledôneas aumentaram em 76 vezes sua produção, considerando antes e após a queima. Informações locais (CASTILHOS \& JACQUES, 1984; FONTANELI \& JACQUES, 1988; EGGERS \& PORTO, 1994) também notificam o aumento na contribuição de dicotiledôneas em detrimento das gramíneas após as queimadas.

Embora o fogo pareça aumentar a taxa de micro sucessão em pequena escala de distúrbio no solo (COLLINS \& GIBSON, 1990), a queima freqüente e sem critérios, poderá promover uma sucessão regressiva na vegetação (MUELLERDOMBOIS \& ELLENBERG, 1974; GRIME, 1979), com perda de espécies e decréscimo na complexidade estrutural, resultante da degradação da área. Já em situações extremas, o fogo associado ao pastejo desordenado pode transformar a pastagem natural em uma monocultura de plantas não nativas (VOGL, 1979).

Nas árvores, a sobrevivência à queima está relacionada à integridade do tecido cambial do caule e raiz. A espessura e tipo de casca são fundamentais para conferir resistência ao fogo. A espessura geralmente aumenta com o diâmetro do caule, o qual depende da idade da planta (BOND \& 
WILGEN, 1996). A partir de uma altura de 2 metros, com idade de 5 a 6 anos (FERREIRA \& IRGANG, 1979), ou com espessura de casca superior a $5 \mathrm{~cm}$, as plantas de araucária são resistentes ao fogo (SOARES, 1990). Em coníferas, o nível de queima da coroa é o mais usado para predizer a mortalidade e depende da altura da chama, arquitetura do dossel, penetração vertical do calor, bem como da taxa de crescimento da planta (BOND \& WILGEN, 1996). Já a brotação das espécies ocorre, principalmente, a partir da base dos caules ou de raízes e rizomas horizontais.

\section{Ação do fogo na comunidade vegetal}

A resposta da comunidade ao fogo, em pequena escala, ocorre através de modificações morfo-fisiológicas dos indivíduos. Em grande escala resulta em uma dinâmica de mosaico da vegetação, que muda de tamanho através de forças combinadas atuando dentro da comunidade. A interação entre fogo e os herbívoros define, freqüentemente, os limites da comunidade (STEUTER \& McPHERSON, 1995). Assim, comunidades adaptadas ao fogo mantêm suas espécies dominantes e atingem a máxima produtividade, quando o fogo ocorre numa frequiência característica.

Quando ocorre um distúrbio maior, semelhante ao fogo, rompe-se o padrão normal em um sistema ecológico, conduzindo ao aumento na oferta de recursos para plantas sobreviventes ao distúrbio, ou às novas colonizadoras (MARTINEZCROVETTO, 1965; GRIME, 1979; TILMAN, 1988).

A diversidade florística poderia ser mantida no máximo, em uma escala intermediária de distúrbio (pastejo e queima moderada) que prevenisse a exclusão de espécies menos competitivas (CONNEL \& SLATYER, 1977). Esta seria uma questão relevante deste distúrbio, não só do ponto de vista ecológico, como também forrageiro, em vista da oportunidade de seleção que os animais em pastejo teriam sobre um conjunto maior de espécies. No entanto, conforme apontam COLLINS \& GIBSON (1990), a maioria dos estudos reportam à diversidade de espécies e a heterogeneidade da pastagem as quais decrescem após o fogo porque a queima reduz a cobertura de espécies intersticiais e aumenta a área ocupada por espécies matriciais. Desta forma, para predizer o efeito ecológico do fogo, nós precisamos conhecer a magnitude desse, induzindo a mortalidade que cria espaços abertos, e a importância da queima, estimulando o desenvolvimento de novas plântulas. Isso torna o fogo um poderoso agente na estruturação de comunidades, desde que as aberturas criadas representem um potencial para mudanças na vegetação (BOND \& WILGEN, 1996).

\section{CONCLUSÃO}

Há evidências de que as queimadas e/ou herbivoria contribuem para manutenção dos campos no regime climático atual e de que a araucária está entre os campos nas regiões altas, não porque seja uma espécie pioneira, mas em função de sua baixa competição com a floresta latifoliada. Também as plantas sujeitas a fogos recorrentes, que permanecem na comunidade, apresentam diversas estratégias para sobreviver, competir e se reproduzir naquele ambiente.

\section{REFERÊNCIAS BIBLIOGRÁFICAS}

AUBREVIlle, A. A floresta de pinho do Brasil. Anuário Brasileiro de Economia Florestal, São Paulo, v.2, n.2, p.21$36,1949$.

BEHLING, $\mathrm{H}$. Investigations into the Late Pleistocene and Holocene history of vegetation and climate in Santa Catarina (South Brazil). Vegetation History and Archeobotany, Berlin, v.4, p.127-152, 1995.

BEHLING, H. Late quaternary vegetation, climate and fire history of the Araucaria forest and campos region from Serra Campos Gerais, Paraná State (South Brazil). Review of Palaeobotany and Palynology, Amsterdam, v.97, p.109-121, 1997.

BLANK, R.R., YOUNG, J.A. Heated substrate and smoke: influence on seed emergence and plant growth. J Range Management, Denver, v.51, n.5, p.577-583, 1998.

BOND, W.J., WILGEN, B.W. van. Fire and plants. London: Chapman \& Hall, 1996. 263p. (Population and community biology, 14).

BRASIL. Inventário florestal do pinheiro no Sul do Brasil. Curitiba : FUPEF, 1978. 327p.

BRASIL. Inventário florestal nacional; Florestas nativas do Rio Grande do Sul. Brasília : IBDF, 1983. 345p.

CASTILHOS, Z.M.S., JACQUES, A.V.A. Produção e qualidade de uma pastagem natural submetida a tratamentos de introdução de trevo vesiculoso cv. Yuchi (Trifolium vesiculosum Savi), ceifa e queima. Anu Téc IPZFO, Porto Alegre, v.11, p.65-112, 1984.

CHRISTENSEN, N.L. Shrubland fire regimes and their evolutionary consequences. In: PICKETT, S.T.A., WHITE, P.S. (Eds.) The ecology of natural disturbance and patch dynamics. London: Academic, 1985. Cap.6. p. $85-100$.

COLLINS, S.L., GIBSON, D.J. Effects of fire on community structure in tallgrass and mixed-grass prairie. In: COLLINS, S.L., WALlACE, L.L. (Eds.) Fire in North American tallgrass prairies. Norman : University of Oklahoma, 1990. p.81-98.

CONNEL, J.H., SLATYER, R.O. Mechanisms of sucession in natural communities and their role in community stability and organization. American Naturalist, Chicago, v.111, p.11191144, 1977. 
COUTINHO, L.M. O uso do fogo em pastagens naturais brasileiras. In: PUIGNAU, J.P. (Ed.). Utilizacion y manejo de pastizales. Montivideo : IICA-PROCISUR, 1994. p.159. 168. (DIALOGO XL)

COUTINHO, L.M. Aspectos ecológicos do fogo no Cerrado. 2. As queimadas e a dispersão de sementes de algumas espécies anemocóricas do estrato herbáceo-subarbustivo. Boletim de Botânica, São Paulo, v.5, p.57-64, 1977.

DAUBENMIRE, R. Ecology of fire in grasslands. Advances in Ecological Research, London, v.5, p.209-266, 1968.

DUARTE, L.S. Respostas ecofisiológicas de plântulas do pinheiro brasileiro (Araucaria angustifolia [Bert.] O. Ktze) a diferentes níveis de irradiância. Porto Alegre, 1997. 57p. Dissertação (Bacharel em Ciências Biológicas) - Universidade Federal do Rio Grande do Sul, Porto Alegre, 1997.

EGGERS, L.; PORTO, M.L Ação do fogo em uma comunidade campestre secundária, analisada em bases fitossociológicas. Porto Alegre : Instituto de Biociências da UFRGS, 1994. 88 p. (Boletim de Instituto de Biociências, 53).

ESTIVALET Jr., C.N.O. Efeitos da ceifa, queima e diferimento sobre a disponibilidade e composição botânica de uma pastagem natural. Porto Alegre, 1997. 97p Dissertação (Mestrado em Zootecnia) - Programa de Pós-graduação em Zootecnia. Universidade Federal do Rio Grande do Sul, Porto Alegre, 1997.

FERNANDES, R.R. Variações estacionais dos teores de umidade e oleorosina em folhagem de Pinus elliottii Engelm, Pinus taeda L. e Araucaria angustifolia (Bert) O. Ktze. e sua influência no potencial de inflamabilidade das copas. Revista Florestal, São Paulo, v.13, v.2, p.42-43, 1982.

FERREIRA, A.G., IRGANG, B.E. Regeneração natural de Araucária angustifolia nos Aparados da Serra-RS. In: CONGRESSO NACIONAL DE BOTÂNICA, 30, Rio de Janeiro, 1979. Anais... Rio de Janeiro : UFRRJ, 1979. p. $225-230$.

FONTANELI, R.S., JACQUES, A.V.A. Melhoramento de pastagem natural: ceifa, queima, diferimento e adubação. Revista Brasileira de Zootecnia, Viçosa, v.17, n.12, p.180194, 1988.

FRANGI, J.L., RONCO, M.G., SANCHEZ, N.E., et al. Efecto del fuego sobre la composición y dinámica de la biomassa de um pastizal de Sierra de la Ventana (Bs. As., Argentina). Darwiniana, Buenos Aires, v.22, n.4, p.565-85, 1980.

GRIME, J.P. Plant strategies and vegetation processes. Chichester : John Wiley, 1979. 203p.

GRIME, J.P., CAMPBELL, B.D. Growth rate, habitat productivity, and plant strategy as predictors of stress response. In: MOONEY, H.A., WINNER, W.E., PELL, E.J. (Eds.). Response of plants to multiple stress. London: Academic, 1991. Cap.7. p.143-159.

HOLDRIGE, L.R. Determinations of world fomations from simple climatic data. Science, New York, v.105, p.367-368, 1947.

KLEIN, R. Aspectos dinâmicos da vegetação do sul do Brasil. Sellowia. Anais Botânicos do Herbário "Barbosa Rodrigues", Itajaí, n. 36, p.5-56, 1984.

KNAPP, A.K. Effect of fire and drought on the ecophysiology of Andropogon gerardii and Panicum virgatum in a tallgrass prairie. Ecology, Washington, v.66, n.4, p.1309-1320, 1985.

MACEDO, M.C.M. A utilização do fogo e as propriedades físicas e químicas do solo. In: SIMPÓSIO SOBRE MANEJO DE PASTAGENS, 12, 1995, Piracicaba. Anais... Piracicaba: FEALQ, 1995. p.315-345.

MARTINEZ-CROVETTO, R. Estudios ecologicos en los campos del sur de Misiones. I. Efecto del pastoreo sobre la estructura de la vegetación. Bonplandia, Corrientes, v.2, n.2, p.1-13, 1965 .

MUELLER-DOMBOIS, D., ELLENBERG, H. Aims and methods of vegetation ecology. New York : John Wiley \& Sons, 1974. 547p.

PILLAR, V. de P., QUADROS, F.L.F. de Grassland-fores boundaries in southern Brazil. Coenoses, Gorizia, v.12, n. 23, p.119-126, 1997

RAMBO, B. História da flora do planalto do riograndense. Sellowia, Itajaí, v.5, n.5, p.182-232, 1953.

RISSER, P.G. Landscape processes and the vegetation of the North American Grassland. In: COLLINS, S.L., WAllaCE, L.L. (Eds.). Fire in North American tallgrass prairies. Norman : University of Oklahoma, 1990. p.133-146.

RIZZINI, C.T. Tratado de fitogeografia do Brasil: aspectos ecológicos. São Paulo : HUCITEC, EDUSP, 1976. Fogo: p.87-111.

ROSENGURTT, B. Estudos sobre praderas naturales del Uruguay- 3 contribución. Montivideo : Hemisferio Sur, 1943. 201p.

SCHÜLE, W. Landscapes and climate in prehistory: interaction of wildlife, man and fire. In: GOLDAMMER, J.G. (Ed.). Fire in the tropical biota. Berlin : Springer-Verlag, 1990 p.273-318.

SOARES, R.V. Fire in some tropical and subtropical South American vegetation types: an overview. In: GOLDAMMER, J.G. (Ed.). Fire in the tropical biota. Berlin: Springer-Verlag, 1990. p.63-81.

STEUTER, A.A., McPHERSON, G.R. Fire as a physical stress. In: BEDUNAH, D.J., SOSEBEE, R.E. Wildland plantas physiological ecology and developmental morphology. Denver: Society for Range Management, 1995. p.550-579.

TILMAN, D. Plant strategies and the dynamics and structure of plant communities. Princeton : Princeton University, 1988. 362p.

VOGL, R.J. Effects of fire on grasslands. In : KOZLOWSKI, T. T., AHLGREN, C.E. (Eds.). Fire and ecosystems. Madison: Academic, 1974. p.139-182.

VOGL, R.J. Some basic principles of grassland fire management. Environmental Management, Madison, v.3, n.1, p.51-57, 1979.

WALLACE, L.L. Epilogue: a search for paradigms. In COLLINS, S.L., WALlACE, L.L. (Eds.) Fire in North American tallgrass prairies. Norman : University of Oklahoma, 1990. p.147-151. 